\title{
11 Personal computing technology: use and possibilities
}

\author{
Adrian Oldknow \\ Chichester Institute of Higher Education \\ W. Sussex, United Kingdom
}

\begin{abstract}
Developments in hand-held, battery-powered computing technology are considered and defined in terms of Personal Computing Technology (PCT). The suitability of PCT for use in supporting teaching and learning mathematics is exemplified in terms of the capability now available with facilities extending from computational to software packages, with word processing, spreadsheets and computer algebra, along with the potential for linking with teaching hardware and desk-top computers. The role of such technology in connection with the professional development of teachers is such that we are now in a position to support national curriculum priorities as well as teacher enhancement with PCT.
\end{abstract}

\section{Keywords}

Classroom practice, graphics/programmable calculators, hand held computers, national policies, teacher education.

\section{INTRODUCTION}

There have been enormous changes in the power and availability of Information and Communication Technology (ICT). There are presently national and international educational initiatives to connect schools, colleges and information providers using high speed communications (so-called super highways) and powerful multi-media desk-top computers. These possibilities are extremely exciting. However, given the real-politik of secondary schools with (usually far) less than perfect human and physical resources, this paper concentrates on a particular form of ICT which seems to be having the greatest impact currently on mathematics teaching and learning in secondary schools - that which we will call Personal Computing Technology (or PCT for short). 


\section{PERSONAL COMPUTING TECHNOLOGY}

One of the earliest applications of the silicon chip, more than 20 years ago, was the electronic calculator. This device has had considerable impact on work, home and education throughout the world - in very diverse ways, and over very different time scales. Developments in associated technologies, such as LCD displays, led, around 10 years ago, to the development of graphing calculators using a display, typically of around $100 \times 64$ pixels. Such calculators, which will be referred to as GCs (for graphing/graphic calculators), were produced by companies such as Casio, Sharp, Hewlett Packard and, later, Texas Instruments. Their impact has been almost exclusively on education, usually at the higher age and ability ranges, and principally in mathematics in the industrialised European and North American countries.

Currently there is a wide range of powerful models of GC available priced between 20 and 120 US dollars. Their common facilities enable the user to:

- enter, edit analyse and display substantial data sets;

- enter functions in algebraic notation, such as:

$y_{1}(x)=2 x+3$ and to produce tables and graphs of values;

- draw figures such as circles, lines, etc., using co-ordinates; and

- enter, edit and run programs written in a simple programming language.

Certain models can exchange data with each other and with personal computers as well as having scientific data capture devices and overlay graphic displays for OHPs. Thus they can no longer be thought of as just a simple development from the four-function and scientific calculators. They are really hand-held microcomputers running a suite of dedicated software for mathematics and science. In some countries they are widely available as consumer electronic products through high-street stores. A few models have the ability to perform symbolic manipulation e.g. for algebra and calculus (also known as CAS, for Computer Algebra System).

Electronic calculators-elementary, scientific and graphing-are clearly compact, low-cost personal ICT tools which are designed for solving mathematical problems. The manufacturers of other electronic products have not been slow to exploit markets where people have need to store and retrieve information while on the move. Hence there have been a proliferation of pocketsized, battery-powered devices such as personal organisers, data-banks and palmtop computers. Many of these are hand-held microcomputers running a suite of dedicated generic software such as a spreadsheet and database-usually with the capacity to communicate with host software on a desk-top computer. Some have the capacity to store data and to run programs using removable media such as flash-card RAM or ROM. An early example of this was a version of the CAS package Derive adapted to run on a Hewlett Packard HP95 palm-top computer.

Now these two strands of technological developments-the graphing calculator and the personal organiser-are coming together in a way which has 
considerable implications for education in general, and mathematics in particular. To illustrate this point consider two recent developments, one in hardware: the Texas Instruments' TI-92, the other in software: the Microsoft Windows CE operating system. The TI-92 is a bold mixture of a graphic calculator (the TI-82) and a palm-top computer with dedicated software for geometry (written by the authors of Cabri Géomètre ${ }^{(8)}$ ) and symbolic manipulation (written by the authors of Derive(8), packaged in a unit whose size and feel reflect another branch of consumer electronics - the hand-held game device. Together with its statistics handling, programming language and text-editor the TI-92 is the mathematician's device par excellence, as demonstrated by Waits and Demana (1995). By contrast Windows $C E$ is an attempt to build a common operating system for palm-top computers which has the feel of other versions of Windows for desk- and lap-top models. Thus new ranges of palm-tops from manufacturers such as Hewlett Packard and Casio are based on this software, with its built-in versions of the common MS Word* word-processing, and MS Excel spreadsheet software. Here it is now up to any third-party software producer to tailor versions of their software to run on these smaller and cheaper platforms.

\section{EDUCATIONAL APPLICATIONS OF PERSONAL COMPUTING TECHNOLOGY}

It is clear from the above that virtually all the forms of software currently found on desk-top computers which have importance for secondary school mathematics now have their PCT equivalents (or soon will have). Physical aspects such as speed, colour, screen resolution, etc., may make the desk-top version (far) preferable for individual use - but compromises have to be made when providing mass, public education. If UK experience is anything to go on, the availability of large numbers of networked computers in specialist rooms has actually brought about a decrease in the use of ICT to support secondary school mathematics teaching. This may be explained by a variety of factors, such as competition with other subjects for resources, teacher anxiety about the technology, or lack of appropriate software. More to the point, it may actually be appropriate only to use such software for just part of a lesson-and the physical disruption involved in organising a room change may well be educationally counter-productive.

Graphic calculators have gained an established place in mathematics in the 16-19 age range in many countries. Partly this can be seen as a result of bottomup pressure from students buying their own equipment, as reported at ICME6 by Oldknow and Taylor (1989). In the UK there are now several syllabuses at this level which have been designed with the assumption that all students have access to GCs. Recent data collected by Ruthven (1997) show how extensive such ownership has become. Other countries, such as Norway and Denmark, which have a national curriculum at this level, are making the use of GCs compulsory. 
A different model is the Advanced Placement examination in the USA where the use of GCs was first banned, then permitted and is now encouraged-with questions set in which access to a GC is essential. The implications of CAS at this level raises many questions about conventional approaches to examination and testing; see Ruthven (1997), Hirlimann (1996), Oldknow and Flower (1996) and Cornu and Ralston (1992, p.93 et seq.). For example, currently the only restrictions on calculators for use in the French Baccalauréat examination are on size and ability to inter-communicate-criteria which the TI-92 passes, CAS and all.

The widespread use of GCs in lower secondary schools (age 11-16 in the UK) is a more recent phenomenon. The first generations of GCs were relatively expensive, relatively user-hostile and could not inter-communicate. In 1993 a government-funded pilot evaluation of Personal Computer Technology took place in England and Wales involving 118 projects in primary schools (ages 5-11), secondary (ages 11-16) and special schools (ages 5-16) covering a wide range of subjects from the national curriculum. The hardware included notebooks, lowcost wordprocessors, palmtops (including HP95 with Derive), graphic calculators and personal organisers. Through this project a group of secondary schools were equipped with relatively large numbers of GCs for work in mathematics. Some had just a class set of 30 , others had enough for 3 or 4 classes $(100+)$, others had enough for every pupil in the 1993 intake (c200). An evaluation of this project was conducted by NFER, (see Stradling et al., 1994).

The following year the government changed its policy on the use of ICT in secondary schools moving the emphasis from the technology itself to its use to support the teaching and learning of a group of subjects: mathematics, science, technology and geography. By this time a new generation of GCs had been developed, such as the Texas Instruments TI-82, which were fully communicating - both with each other, and with desk-top computers, and hence to printers. Thus students were able to get hard-copy of their work. Similarly teachers equipped with OHP capabilities for use with such GCs could both demonstrate their output to the class, and also display results obtained by pupils.

Through these facilities teachers have now become able to make their own decisions about how best to deploy the technology. Some choose a personal ownership model in which pupils borrow GCs for a period of time, others prefer to hand them out for use only in class. Some prefer all pupils to have their own, others prefer them to be shared by groups of 2 or 3 to encourage discussion. A clear factor in schools deciding to adopt this technology is the price. A whole class can be equipped for the price of 2 desk-top computers (see, e.g., Ruthven, 1996)

Perhaps the most exciting development has been that in data-capture and control devices which are compatible with GCs. Both Texas Instruments and Casio manufacture hand-held, battery-driven data-loggers which can accept a wide variety of sensors and probes. These include sensors for temperature, voltage, light, sound, $\mathrm{pH}$, and radiation, as well as heart-rate monitors, strain 
gauges and motion detectors. They can be programmed from the calculator and used either remotely or with a GC. Once the data have been downloaded to the GC (possibly in real-time) they can be displayed and analysed. Of course they can also be shared between other GCs, as well as being downloaded to a desk-top computer. This means they can be easily used on field-trips, as well as in minimally equipped school rooms. Another recent development is an integrated sensor which also works directly with a GC and which measures time and distance-called a calculator-based ranger (CBR). This year the UK government is funding a small scale development involving a group of secondary schools (ages 11-16) in which the science and mathematics departments are planning joint work using calculator-based laboratory, CBR and GCs.

\section{EDUCATIONAL IMPLICATIONS OF PERSONAL COMPUTING TECHNOLOGY}

As has already been mentioned there is a difference in the genesis between computational PCT (calculators and GCs) and the more generic palm-tops, personal organisers and the like. This is reflected in the public perception of the products where the first are seen as being just calculators (and therefore probably bad for the pupils!) and the second are clearly small computers. Again, as has already been stated, the modern range of GCs are far more 'computer than calculator', and the difference between the types of such technology is becoming very blurred. However the GC is seen as a tool only for use in the mathematics department. Thus it not surprising that the educational decision makers in secondary schools who control the ICT purse strings have difficulty in understanding that there is a strong argument for seeing PCT in general, and GC based products in particular, as a valid and cost-effective solution to improving teaching and learning in maths, science and related subjects. So there is a communication gap to be overcome. The National Curriculum for mathematics, science and technology in England and Wales (ages 5-16) contains specific references to calculator and ICT use in mathematics, and to data-capture and modelling in science and technology-which should help focus some minds. In the end, though, it is often the stick, rather than the carrot, which has the most effect. Recent policy statements from the UK government make it increasingly likely that all schools will have to have development plans for their ICT strategy - and that these will be subject to regular inspection, with funding implications linked to the outcome.

From the national perspective there is always a concern about what should be in the curriculum, and how it should be assessed. In the first respect it is quite important that there should be an experience and research base to justify using ICT (and hence PCT) in the mathematics curriculum (see, e.g., Burton and Jaworski, 1995, Chapter 4). Fortunately this is now the case (see, e.g., Burton and Jaworski, 1995; Fey and Hirsch, 1992; Dunham and Dick, 1994). In particular 
there are interesting results concerning the education of girls (see, e.g., Burton and Jaworski, 1995, Chapters 10 and 11). Interestingly, recent populist claims that national under-performance in comparative international tests is linked to over reliance on calculators are not born out by the facts, as has been demonstrated in a number of recent reports commissioned in the UK by the Schools Curriculum and Assessment Authority (SCAA), (see, e.g., Ruthven, 1997). Such international tests, in general, do not include questions relating to pupils' ability to use calculators, although this a statutory part of some nations' mathematics curricula.

With regard to assessment, a major concern is the maintenance of standards. Again, populist opinion has been voiced in the UK to suggest that public examinations are becoming easier. SCAA has worked with the Office for Standards in Education (Ofsted, formerly known as Her Majesty's Inspectors of school's or HMI) to look at standards in public examinations over the past 20 years in Mathematics, English and Chemistry at both age 16 (GCSE) and 18 (Alevel). Their report, SCAA/Ofsted (1996), shows interesting inconsistencies between their recommendations in mathematics.

Mathematics at $16+\ldots . .$.

SCAA should establish agreement on the best ways for GCSE syllabuses to ensure that:

- all candidates take papers which must be completed without the use of a calculator and which involve specified skills in mental and written calculation;

- candidates are set some demanding mathematical tasks which require them to demonstrate effective use of the capabilities of calculators.

Mathematics at 18+

In revising and monitoring GCE A-levels, SCAA should work with the examination boards to:

- introduce strict limits on the use of calculators in certain papers.

In the latter case the current questions have little to do with numeric computation. The commentary reads:

Before the introduction of calculators, high proportions of the marks in statistics papers were awarded for calculating standard deviations, correlation coefficients and other quantities ... In the last 15 years or so, statistics courses and examinations have increasingly focused on the selection of suitable approaches to solving problems and the interpretation of results. The use of calculators has allowed the setting of more challenging questions in this area. However, as calculators have become more and more 
powerful, their influence on pure mathematics papers has raised concerns..

So the UK reference is really to facilities associated with GCs, which are currently allowed in both GCSE and A-level examinations. The recent French directions for $97 / 98$ about the use of PCT at 16-19 are more explicit.

\section{Use of programmable calculators or pocket computers} The objective for using programmable calculators or pocket computers in mathematics is not just to perform calculations, but also to check results and encourage sound use of ICT.

Students must know how to use their own equipment in situations related to the curriculum.

The following capabilities are essential basics:

to know how to

- perform numeric operations and to compare numbers;

- use and evaluate those functions required at each stage of the curriculum;

- draw their graphs on the screen;

- use sequential and conditional instructions in a program.

Students are advised to have a suitable machine whose facilities, particularly graphic ones, allow them meet the objectives above. In order to be used in other subjects, and for further study, it must also have statistical functions (for 1 and 2 variables).

\section{PROFESSIONAL DEVELOPMENT OF TEACHERS}

While a most important aspect of PCT is the possibility of individual ownership and use by pupils, its effective use in supporting the mathematics curriculum is in the hands of teachers. They need to know more about the use of technology than can just be found from manuals, teaching materials and other information sources.

To quote Cornu (Cornu and Ralston, 1992, Chapter 8):

Mathematics is evolving and changing under the influence of computers and informatics. Therefore, teachers need to maintain their mathematics knowledge and to practice mathematics from an informatics viewpoint. Mathematics is becoming more experimental, more algorithmic, more numerical; teachers must be able to follow the evolution of mathematics, and to acquire new competencies and new attitudes and to be able to carry out new activities in mathematics. 
Here, again, the flexibility, and cost, of PCT-compared with conventional computer-based alternatives-means that both formal and informal hands-on sessions of staff development are more easily staged, and followed-up. For several years my University has been able to run courses for secondary teachers, both inpost training, INSET, and in initial training, ITT, of around 60 hours over periods between one and three months involving a mixture of formal sessions, a day or half-day in a centre with a tutor, informal sessions, teachers working in local small self-help groups, and private study. These are based on the use of GCs and those teachers without access to one of their own are loaned one for the duration of the course.

A far more extensive programme of teacher development based on PCT has been developed by Waits and Demana in the USA. This programme, Teachers Teaching with Technology (known as T-cubed or $\mathrm{T}^{3}$ ) is now being extended to many other countries, and the UK version was piloted in 96/97. The delivery model fits very well with that already described, but there are considerable advantages in having a national infrastructure so that, for example, information about the courses is widely disseminated, the necessary equipment is provided at the right place, at the right time, and that there is a good set of supporting materials related to the nation's curriculum.

\section{CONCLUSION}

The claim has been made that current forms of PCT are powerful enough to enable nearly all the activities to support the mathematics curriculum usually associated with desk-top computers to be implemented practicably, and more affordably, in (and outside) ordinary classrooms. This extends to related subjects such as science. There are possible problems at the local and national levels in getting PCT products recognised as bona fide ICT products. Some countries have developed strategies to overcome these. The practicability of PCT extends beyond pupil use into training and support activities for teachers. There are good models and good materials currently in place. Technological developments are such that PCT products are unlikely to become obsolete, and evaluations of their use show them to be extremely reliable. They may well provide a viable alternative to conventional computers for countries (or districts, states, counties etc.) considering establishing a place for ICT in the mathematics curriculum.

\section{REFERENCES}

Burton, L. and Jaworski, B. (eds.) (1995). Technology in Mathematics Teaching. Bromley: Chartwell-Bratt.

Cornu, B. and Ralston, A. (eds.) (1992). The influence of computers and informatics on mathematics and its teaching. Paris: UNESCO. 
Dunham, P. and Dick, T. (1994). Research on Graphing Calculators, The Mathematics Teacher, 87(6), 440-445.

Fey, J. and Hirsch, C. (eds.) (1992). Calculators in Mathematics Education. Reston VA: National Council of Teachers of Mathematics.

Hirlimann, A. (1996) Computer Algebra Systems in French secondary schools, The International Derive Journal, 3(3) $1-4$.

Oldknow, A. and Flower, J. (eds.) (1996). Symbolic Manipulation by Computers and Calculators. Derby: The Mathematical Association.

Oldknow, A. and Taylor R. (1989). Mathematical Activity Generated Through Hand-held Graphical Calculators, in J. Malone, H. Burkhardt and C Keitel (eds.) The Mathematics Curriculum: Towards the Year 2000. Perth: Curtin University of Technology.

Ruthven, K. (1996). Calculators in the mathematics curriculum: the scope of personal computer technology. In A. Bishop, K. Clements, C. Keitel, J. Kilpatrick and C. Laborde (eds.) International Handbook of Mathematics Education. Dordrecht: Kluwer.

Ruthven, K. (1997). Computer algebra systems in advanced-level mathematics. London: School Curriculum and Assessment Authority.

SCAA/Ofsted (1996). Standards in Public Examinations 1975 to 1995. London: School Curriculum and Assessment Authority.

Stradling, R, Sims, D. and Jamison, J (1994). Portable Computers Pilot Evaluation Report. Coventry: National Council for Educational Technology.

Waits, B. and F. Demana (1995). The TI-92: The next revolution in hand-held computer enhanced mathematics teaching and learning. Colombus $\mathrm{OH}$ : The Ohio State University.

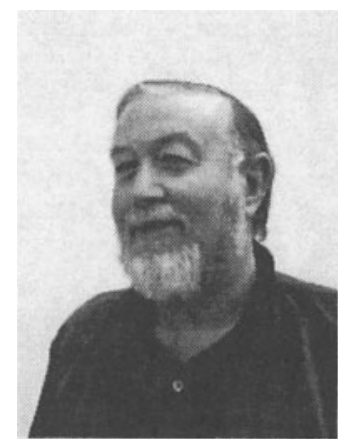

Adrian Oldknow took a mathematics degree at Oxford and taught mathematics in secondary schools, further and higher education; also mathematical education in initial and in-service training for primary and secondary school teachers. In the early 1970's he became involved with computing, and took a Master's degree in Computer Science. Thus began his deep interest in the symbiotic relationship between mathematics and computing where each discipline is now necessary for the development of the other. He retired from teaching in 1997 but continues a wide involvement in national and international educational development. He is now Professor Emeritus at University College Chichester. 